EGTRIB Journal

JOURNAL OF

THE EGYPTIAN SOCIETY OF TRIBOLOGY

VOLUME 17, No. 4, October 2020, pp. 12 - 22 ISSN 2090 - 5882

(Received July 4. 2020, Accepted in final form August 08. 2020)

www.egtribjournal.com

\title{
SLIDING OF POLYETHYLENE COMPOSITES ON ARTIFICIAL TURF
}

\author{
Ali A. S. ${ }^{1}$, Ali W. Y. ${ }^{2}$ and Ibrahem R. A. ${ }^{3}$ \\ ${ }^{1}$ Mechanical Engineering Dept., Faculty of Engineering, Suez Canal University, EGYPT. \\ ${ }^{2}$ Department of Production engineering and Mechanical Design, Faculty of Engineering, Minia University, \\ El-Minia, EGYPT. \\ ${ }^{3}$ Mechanical Engineering Dept., Faculty of Engineering, Beni-Suef University, Beni-Suef, EGYPT.
}

\begin{abstract}
Artificial turf made of polyethylene (PE) fibers is extensively applied in sport yards. It offers cheaper and carefree alternative for natural turf. The high magnitude of electrostatic charge (ESC) generated from polyethylene (PE) fibers has negative effects on the safety of the players. The present experiments aims to decrease ESC generated from contact and separation as well as sliding of conventional rubber soles by developing PE composites filled by metallic particles such as aluminum (Al), copper ( $\mathrm{Cu}$ ) and Iron (Fe).
\end{abstract}

The present experiments revealed that Al film tested as sole surface gained the lowest ESC, while Fe showed the highest ESC followed by $\mathrm{Cu}$. That observation can be explained on the bases that the good electrical conductivity of metallic film homogeneously distributed the charge on the contact surfaces. The high value of ESC recorded for Fe film may be from the influence of the magnetic field generated from ESC. This was confirmed by values of ESC that proportionally increased with the increase of the magnetism of the metallic films. PE composites generated relatively higher values than PE free of metals. Drastic decrease in ESC was observed for the metallic film coated by PE sheet. It is recommended to apply those composites as sole materials for floor covered by $P E$ turf.

\section{KEYWORDS}

Polyethylene composites, artificial turf, electrostatic charge, contact and separation, sliding.

\section{INTRODUCTION}

Artificial turf is manufactured from polyethylene fibers to replace natural grass, [1]. It is extensively used in sport yards, roof gardens, swimming pool surrounds and kid schools. The major drawbacks of artificial turf is the generation of ESC as result of contact and separation as well as sliding of rubber soles, [2 - 4]. PE turf has a tendency to gain ESC when rubbed with human skin especially in dry sliding. This behavior represents major disadvantage for the PE turf. It was found that the surface protrusions of the turf fiber influenced ESC generation. PE turf of smooth surface generated the highest ESC values 
when football shoes slid against it. Besides, friction of PE turf and human skin may cause abrasions and burns in sports. In condition of limited rainfall, there is an increasing demand to apply PE turf.

Tests were carried out on the fibers of PE turf to guarantee the safety of sport players against the abrasion of the turf. It was revealed that the types and depth of infill materials of turf influence the performance of players, [5], by controlling the friction of PE turf with the skin, [6, 7]. It was aimed to decrease abrasion of skin by turf, [8 - 10], by studying the surface properties of PE turf to specify their influence on their skin abrasion, [11 - 13]. The dimension of the fiber materials as well as infill materials control the mechanical behavior of PE turf, [14 - 17]. Simulation of skin using silicone and foam was carried to study abrasion of the turf during sliding in football yard, [18 - 20].

Recently, several attempts were carried out to reduce ESC. It was found that, the material of the substrate of PE fibers significantly influences ESC, [21]. It was found that PE fibers blended by $\mathrm{Cu}$ textile showed drastic decrease in ESC, [22]. The lowest ESC values were recorded in the presence of $\mathrm{Cu}$ substrate instead of $\mathrm{PE}$. Besides, Al film coating the soles recorded the lower ESC values. It was proposed to coat surface of the soles by conducting material to redistribute ESC on PE fibers and transmit to $\mathrm{Cu}$ textile in order to reduce its accumulation on the sliding surface.

It was proposed to blend the turf material by another one of opposite charge, [23]. It was found that the blend generated lower ESC compared to PE turf. Polypropylene (PP) fibers coated by polyurethane (PU) reduced ESC. Besides, coating 80 vol. \% of PE fibers by PU in artificial turf drastically decreased ESC. It was recommended to blend PE turf by PU fibers to replace PE turf. PE fibers were blending by yarns and textile of polymethyl methacrylate (PMMA) and polyamide (PA) that gain positive ESC, [24]. When the content of PA yarns blending PE turf increased, ESC decreased. Ribbons of PA textiles drastically reduced ESC. ESC generated from sliding of aluminum (Al) film, copper (Cu) textile and carbon fibers (CF) on PE turf blended by polymethyl methacrylate (PMMA) yarns and polyurethane (PU) fibers was tested, [25]. The results showed that Al film gained the highest ESC followed by $\mathrm{Cu}$ textile and $\mathrm{CF}$.

The present paper proposes PE composites filled by metallic powders to be used as soles to reduce ESC generated during their contact and separation as well as sliding on PE turf at dry contact condition.

\section{EXPERIMENTAL}

The surfaces of the test specimens consisted of three types. The first was metallic particles layer of $0.25 \mathrm{~mm}$ thickness adhered into the wooden cube. The metallic particles of 30 $50 \mu \mathrm{m}$ particle size were aluminum ( $\mathrm{Al})$, copper $(\mathrm{Cu})$ and iron $(\mathrm{Fe})$. The second was layer of $\mathrm{PE}$ and $\mathrm{PE}$ composites filled by metallic particles, while the third was PE composites layer coated by $0.25 \mathrm{~mm}$ PE sheet, Fig. 1. ESC generated from the contact and separation as well as sliding of the test specimens on PE turf was measured. The tested PE turf is shown in Fig. 2. PE composites of $5 \mathrm{~mm}$ thickness were adhered to one surface of wooden cube of $40 \times 40 \times 40 \mathrm{~mm}^{3}$. The PE surface was loaded to the turf surface at weight of 15.0 
$\mathrm{N}$. Then the cube was manually pulled and moved horizontally at dry sliding. PE fiber length, width and thickness were $60,2.0,0.22 \mathrm{~mm}$ respectively. The arrangement of the test procedure is shown in Fig. 3. Surface DC Voltmeter SVM2 recorded the values of ESC generated on the surface of PE fibers and PE composites, where readings were performed by sensor $25 \mathrm{~mm}$ apart from the tested surface.

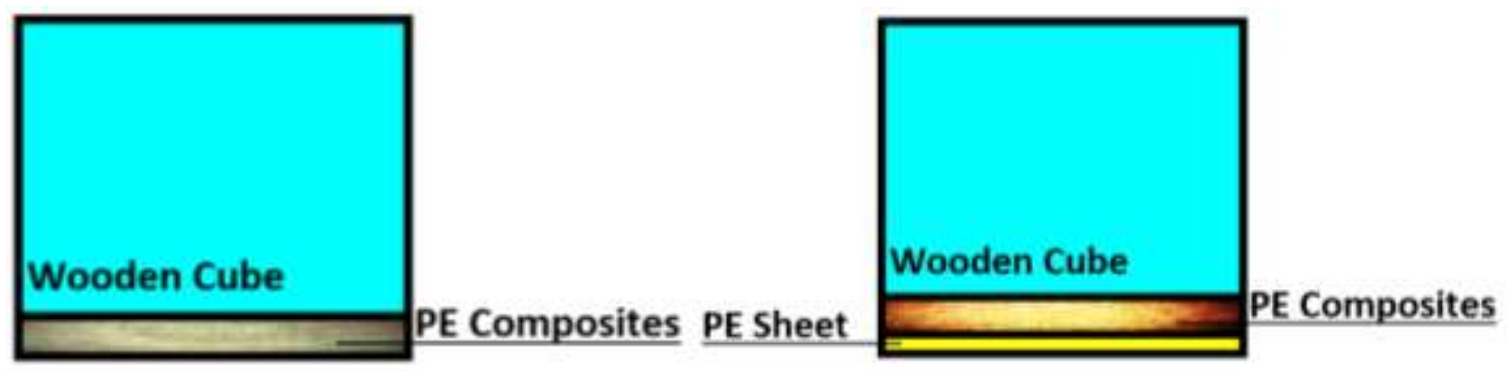

Fig. 2 Test specimens.

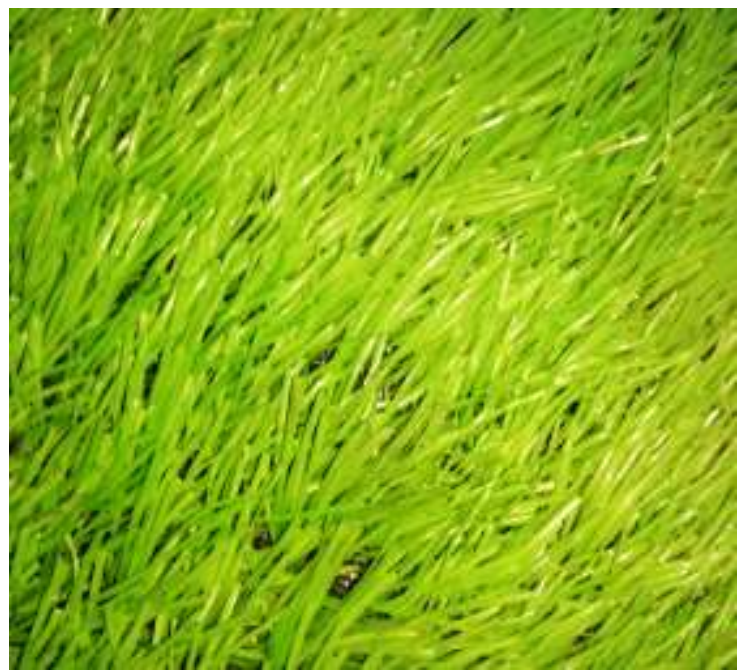

Fig. 2 The tested PE turf.

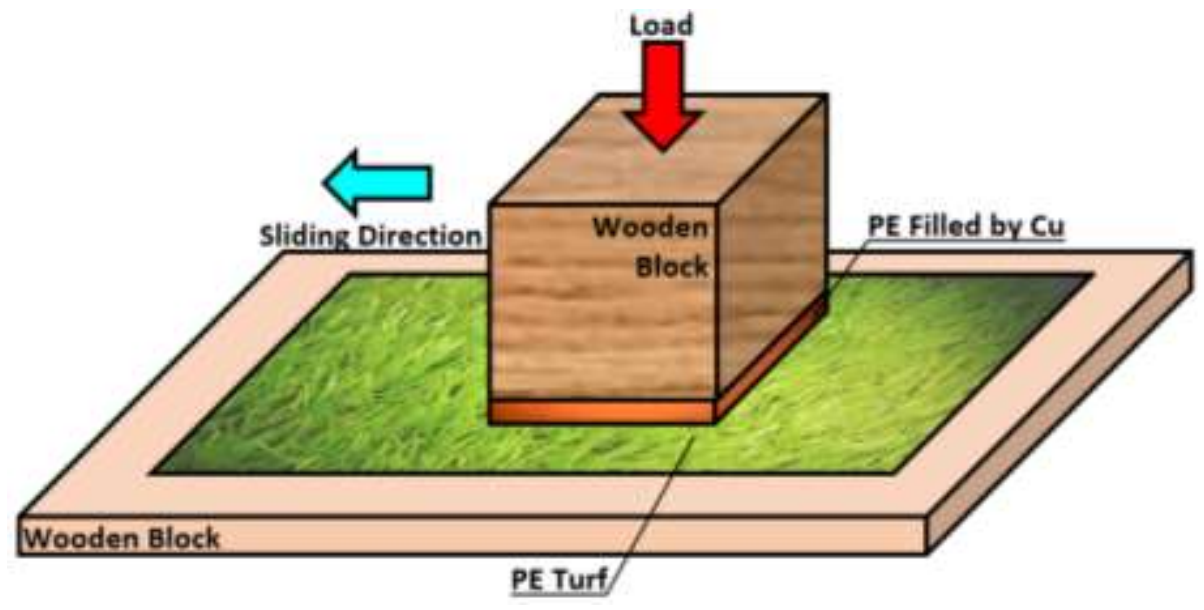

Fig. 3 The arrangement of the test procedure. 


\section{RESULTS AND DISCUSSION}

The results of experiments carried out to investigate the effect of the metallic films on ESC generated during contact and separation of test specimens and turf are shown in Fig. 4. It is shown that Al film gained the lowest ESC, while Fe showed the highest ESC followed by $\mathrm{Cu}$. The magnitude of ESC measured on the turf was higher than that measured on the metallic films. It seems that the good conductivity of metallic film homogeneously distributed the charge on the sole and turf surfaces. The high values of ESC recorded for Fe film may be from the influence of the magnetic field generated from ESC in the presence of $\mathrm{Fe}$ particles. This explanation is supported by values of ESC that proportionally increased with the increase of the magnetism of the metallic material. At sliding, the same trend was observed with relatively higher ESC values, Fig. 5. The highest ESC values (-1750 Volts) were observed for turf when Fe film slid on it.

The contact surfaces of the metallic film was coated by PE sheet of $0.25 \mathrm{~mm}$ thickness in an attempt to decrease ESC in contact and separation as well as sliding, Figs. 6 and 7 respectively. As result of that, drastic decrease in ESC was observed in the presence of PE sheet. This behavior may be attributed to the action of PE sheet that isolated the metallic particles and prevented their contact with PE turf.

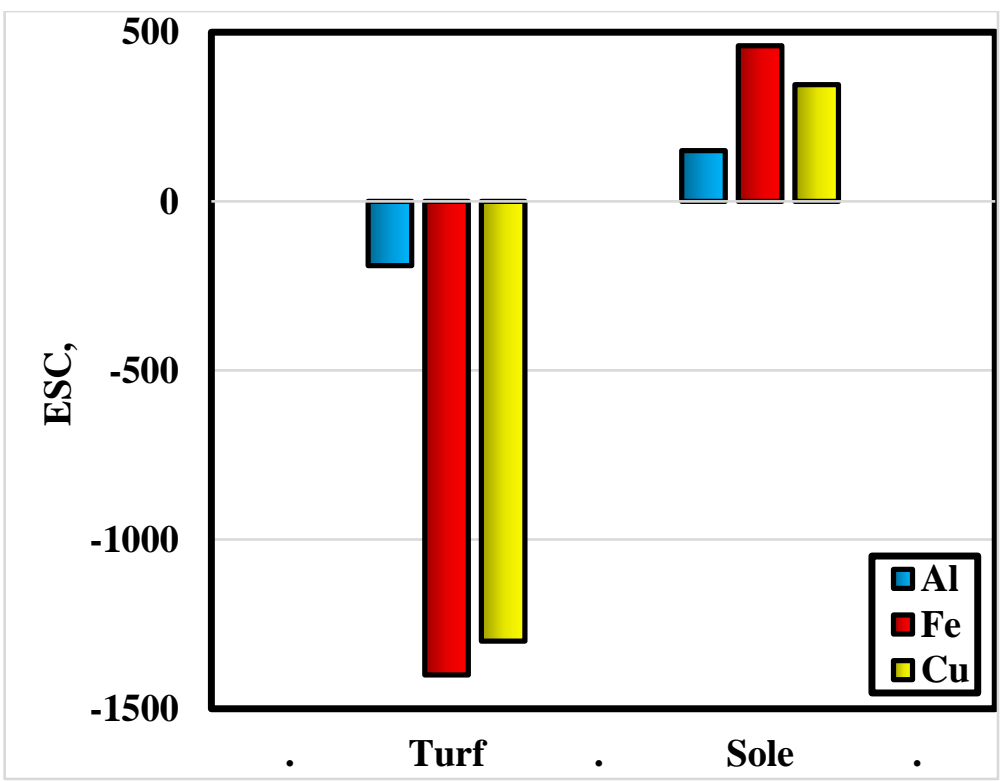

Fig. 4 ESC generated during contact and separation of sole and turf.

When PE composites filled by metallic particles and slid on the tested turf, PE free of metals showed the lowest values of ESC at contact and separation, Fig. 8, where the values were $\mathbf{- 1 4 0}$ and 270 Volts for turf and sole respectively. PE composites generated higher

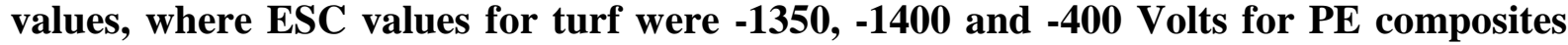
filled by Al, Fe and $\mathrm{Cu}$ respectively. During sliding, Fig. 9, turf gained the highest ESC 
when PE free of metallic particles slid on it. PE composites gained higher ESC values than that recorded for contact and sliding.

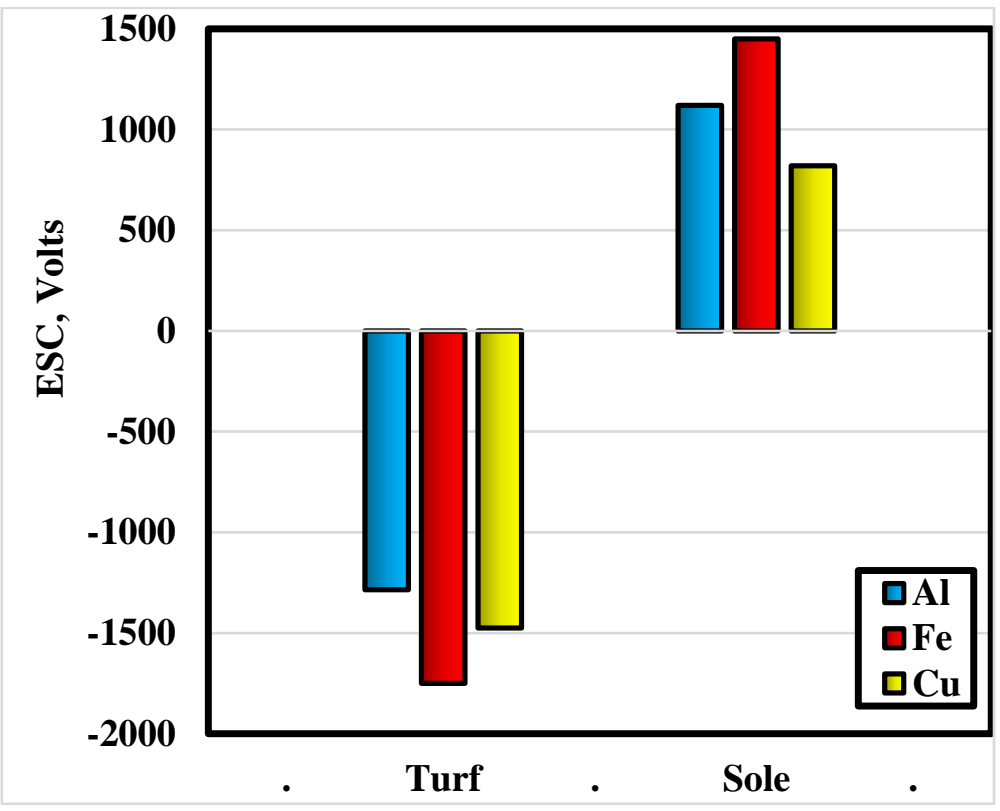

Fig. 5 ESC generated during sliding of sole on turf.

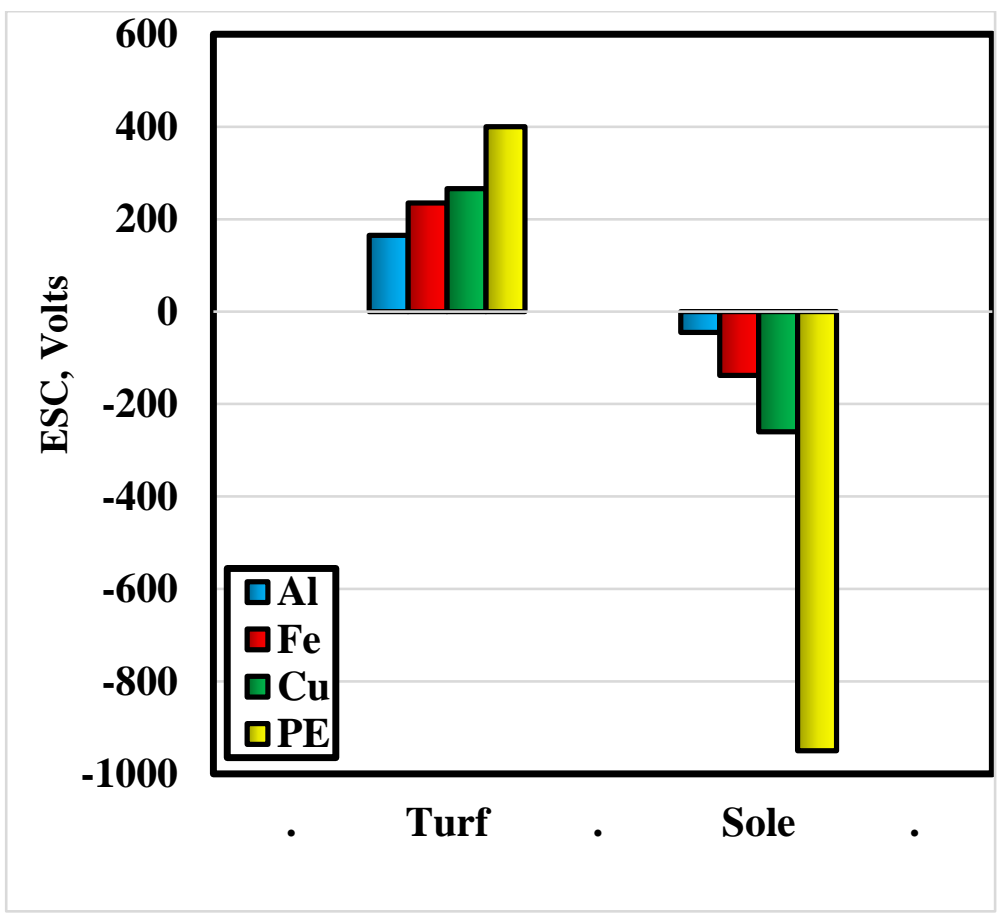

Fig. 6 ESC generated during contact and separation of PE sheet and turf. 


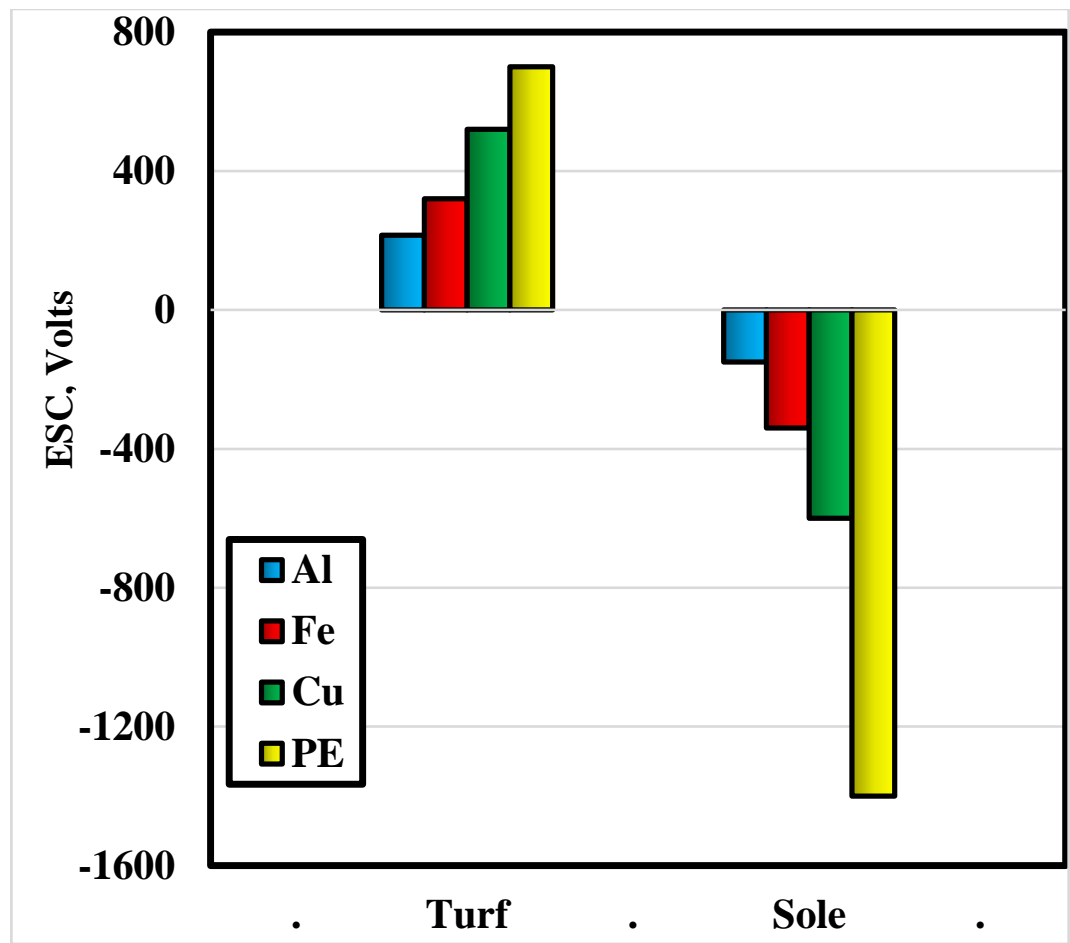

Fig. 7 ESC generated during sliding of PE sheet and turf.

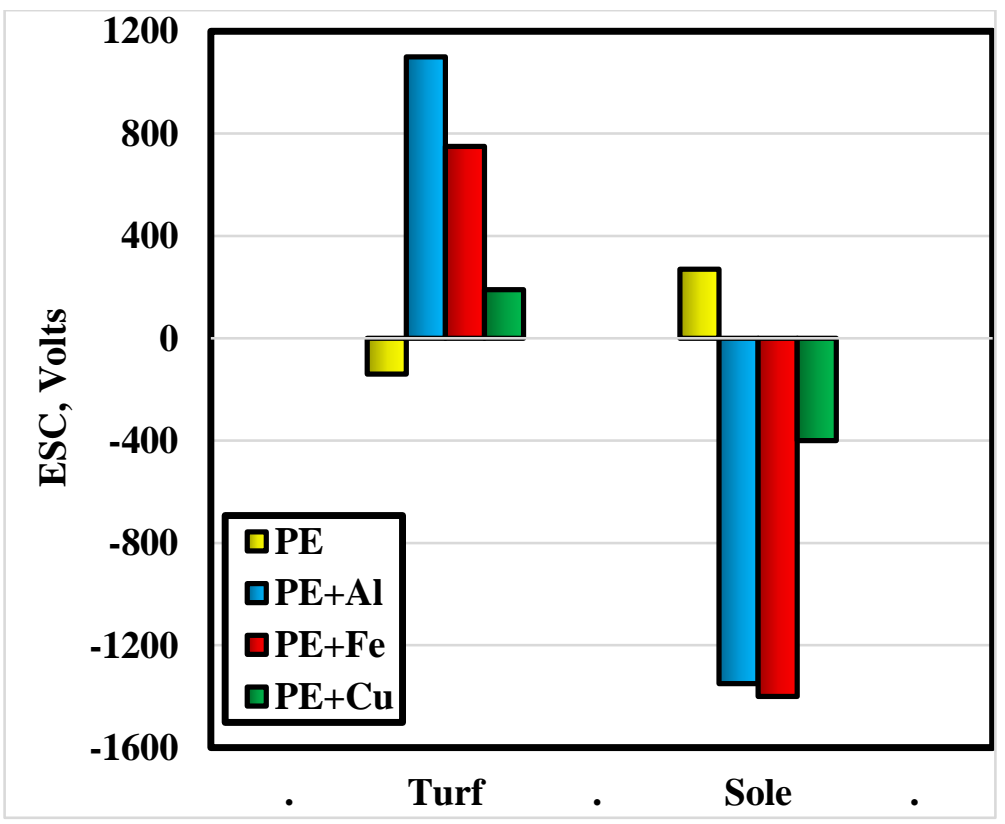

Fig. 8 ESC generated during contact and separation of sole and turf. 


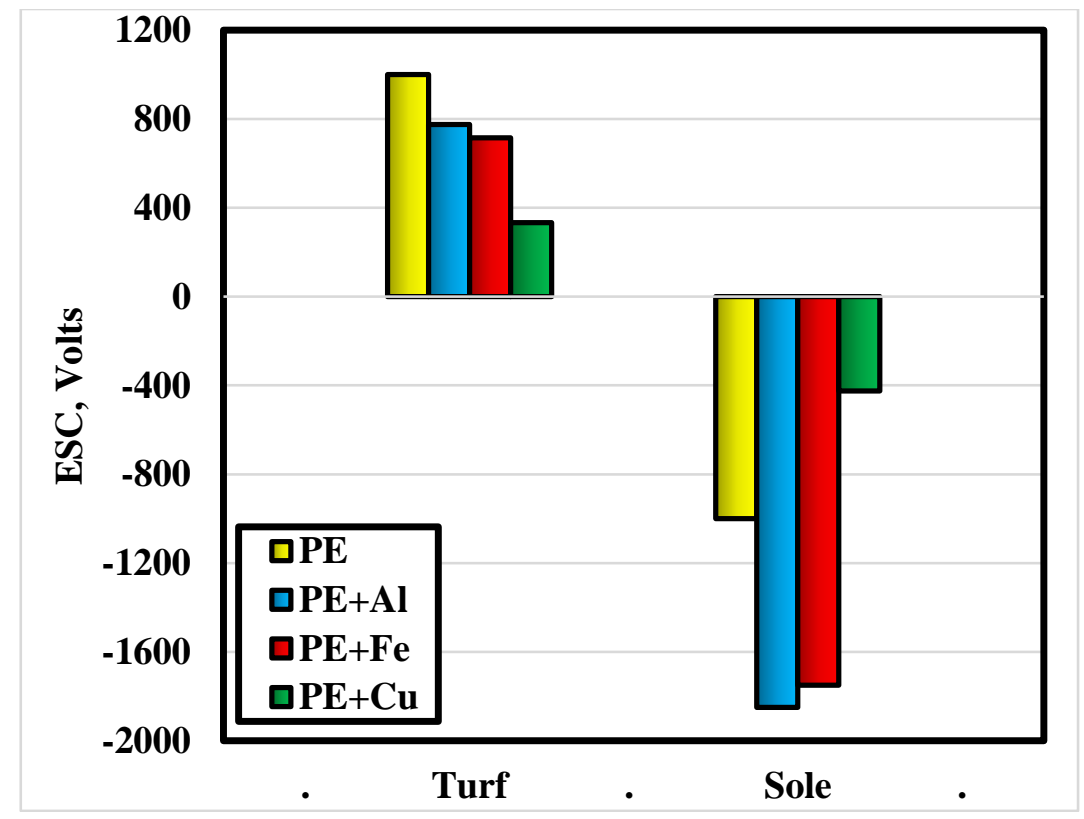

Fig. 9 ESC generated during sliding of sole on turf.

The contact of the tested composites with PE turf is illustrated in Fig. 10. When PE particles slid on PE turf, it was expected that the generated ESC displayed relatively lower values because the two materials are similar, while metallic particles such as $\mathrm{Fe}, \mathrm{Cu}$ and Al showed higher values of positive charge. $P E$ turf gains negative charge higher than that recorded when PE particles slid on PE turf. This fact depends on the position of the sliding materials in the triboelectric series, Table 1. The signs and intensity of ESC during sliding of PE composites on PE turf is shown in Fig. 11, where PE turf gained extra negative ESC due to the friction of the metallic particles.

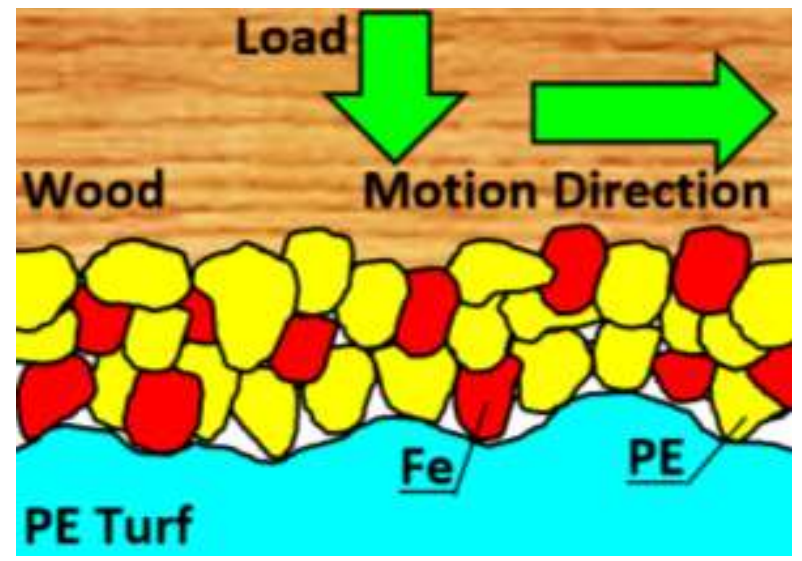

Fig. 10 Contact of the composite with PE turf. 


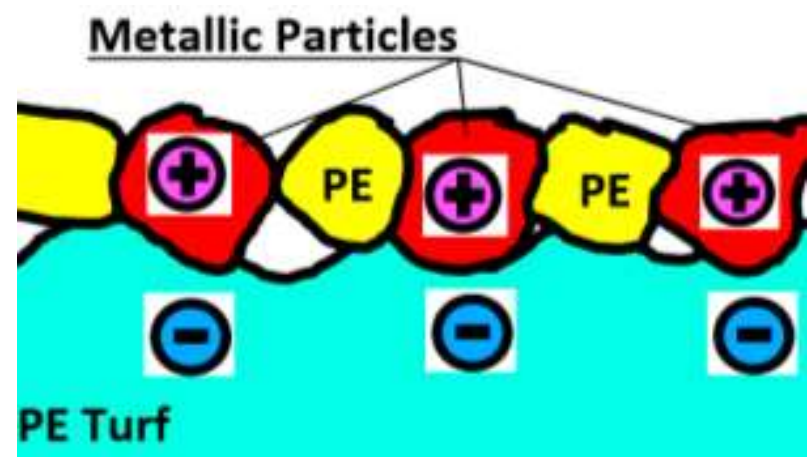

Fig. 11 Signs and intensity of ESC during sliding of PE composites on PE turf.

1 Triboelectric series of the tested materials.

\begin{tabular}{|c|}
\hline Positive charge \\
\hline Aluminum \\
\hline Iron \\
\hline Copper \\
\hline Polyethylene \\
\hline Negative charge
\end{tabular}

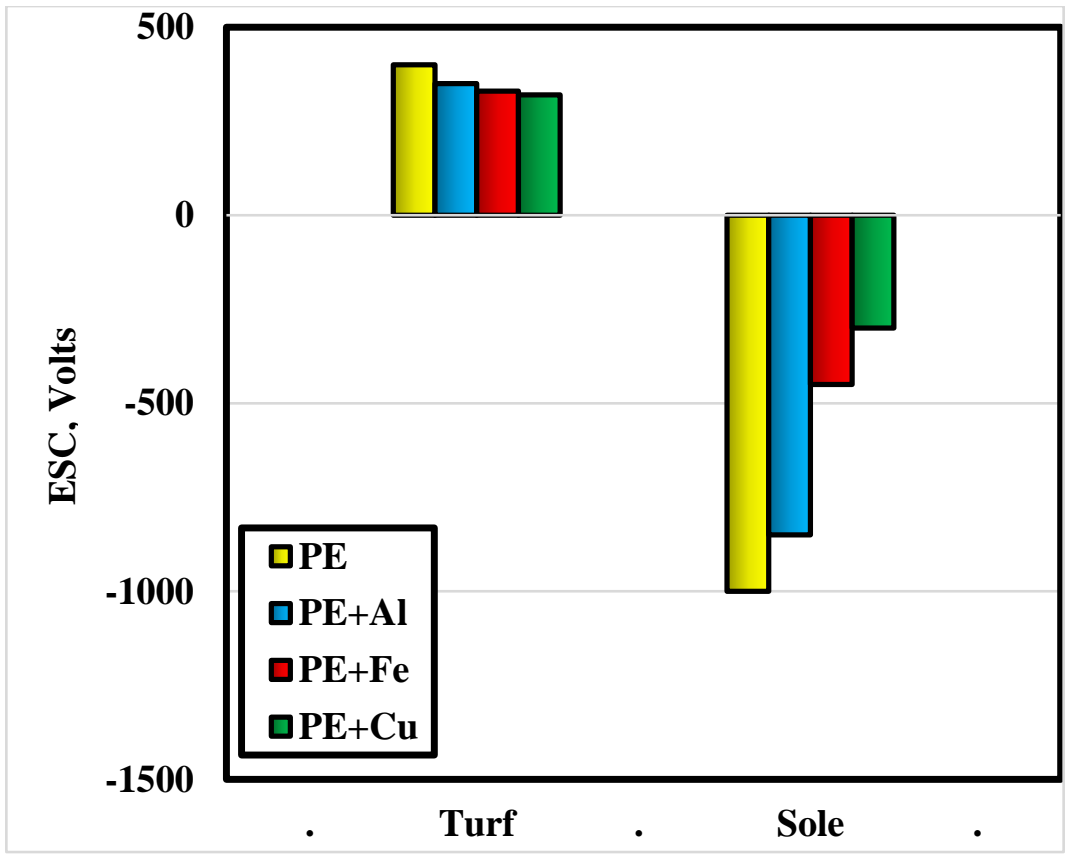

Fig. 12 ESC generated during contact and separation of PE sheet and turf. 


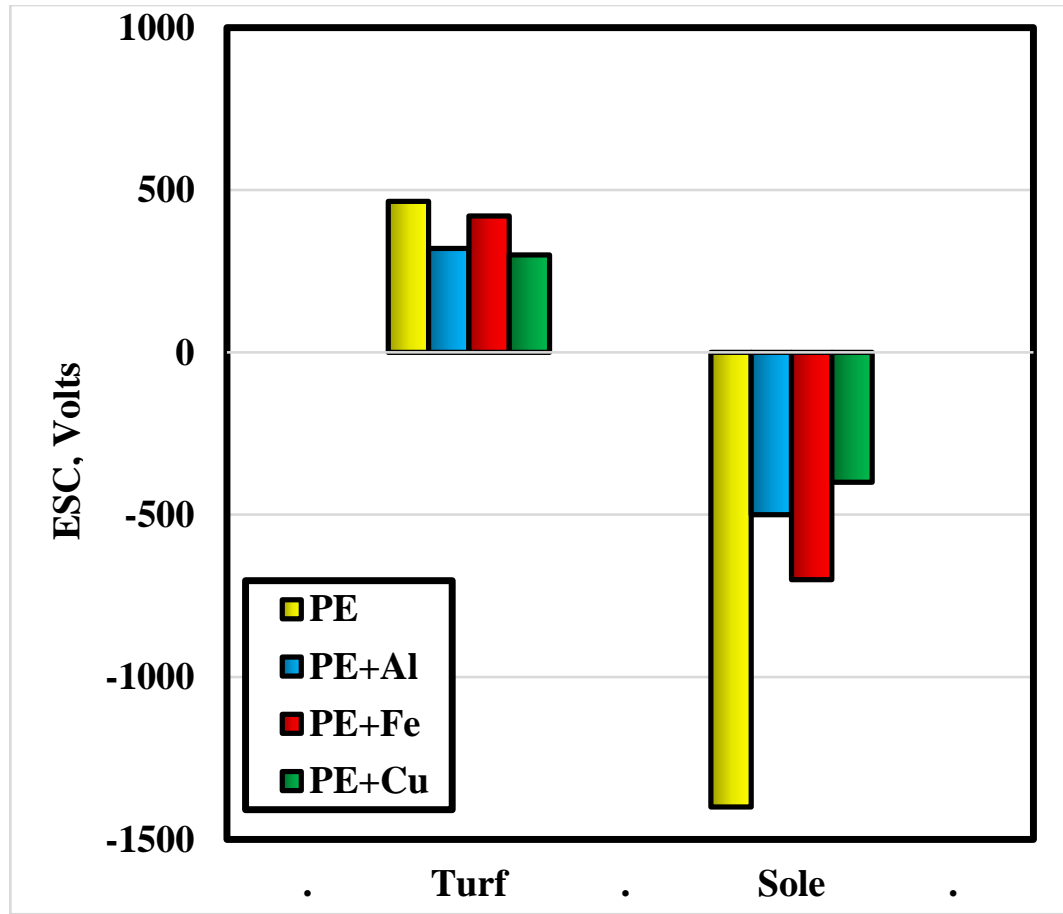

Fig. 13 ESC generated during sliding of PE sheet and turf.

Coating PE composites by PE sheet caused favorable decrease in ESC for both turf and soles at contact and separation as well as sliding, Figs. 13 and 14 respectively. This behavior may be attributed to the function of PE sheet that isolates the contact of metallic particles with PE turf and consequently decreases the magnitude of the generated ESC. That observation recommends those composites to be applied as sole materials used for footwear on floor covered by PE turf. The contact was between PE sheet and PE turf, therefore, ESC displayed relatively lower values. It was interesting that PE coating free of metallic particles coated by PE sheet displayed higher ESC values than the other filled tested composites.

\section{CONCLUSIONS}

1. Among the metallic films tested, Al film gained the lowest ESC, while Fe showed the highest ESC followed by $\mathrm{Cu}$. This observation recommends Al film to coat the surface of the footwear. Magnitude of ESC measured on the turf was higher than that measured on the metallic film. At sliding ESC showed higher values than that observed for contact and separation.

2. PE composites generated relatively higher values than $P E$ free of metallic particles.

3. Coating PE composites by PE sheet caused favorable decrease in ESC. It is recommended to apply those composites as sole materials for floor covered by $\mathrm{PE}$ turf.

\section{REFERENCES}

1. Zanetti E. M., Bignardi C., Franceschini G., Audenino A. L., "Amateur Football Pitches: Mechanical Properties of the Natural Ground and of Different Artificial Turf 
Infills and their Biomechanical Implications", J. Sports Sci 2013, 31 (7), pp. 767 - 778. (2013).

2. Shoush K. A., Elhabib O. A., Mohamed M. K., and Ali W. Y., "Triboelectrification of Epoxy Floorings", International Journal of Scientific \& Engineering Research, Vol. 5, Issue 6, June 2014, pp. 1306 - 1312, (2014).

3. Elhabib O. A., Mohamed M. K., AlKattan A. A. and Ali W. Y., "Triboelectrification of Flooring Polymeric Materials", International Journal of Scientific \& Engineering Research, Volume 5, Issue 6, June 2014, pp. 248 - 253, (2014).

4. Samy A. M. and Ali W. Y., "Effect of the Thickness and Width of Artificial Turf Fiber on the Friction and Electrostatic Charge Generated During Sliding", Journal of the Egyptian Society of Tribology, Vol. 16, No. 2, April 2019, pp. 48 - 56, (2019).

5. Elisabetta M. Zanetti, "Amateur Football Game on Artificial Turf: Players' Perceptions", Applied Ergonomics, 40, pp. 485 - 490, (2009).

6. Tay S. P., Fleming P., Forrester S., Hu X., "Insights to Skin-Turf Friction as Investigated using the Securisport", 7 th Asia-Pacific Congress on Sports Technology, APCST 2015, Procedia Engineering 112, pp. 320 - 325, (2015).

7. Fleming P., Ferrandino M., Forrester S., "Artificial Turf Field - A New Build Case Study", 11 ${ }^{\text {th }}$ Conference of the International Sports Engineering Association, ISEA 2016, Procedia Engineering, 147, pp. 836 - 841, (2016).

8. Tay S. P., Hu X., Fleming P., Forrester S., "Tribological Investigation into Achieving Skin-Friendly Artificial Turf Surfaces", Materials and Design, 89, pp. 177 - 182, (2016). 9. Fleming P., "Artificial Turf Systems for Sport Surfaces: Current Knowledge and Research Needs", Proc. Inst. Mech. Eng. Part P J. Sport. Eng. Technol., 225, pp. 43 - 62, (2011).

10. Junge A., Dvorak J., "Soccer Injuries: A Review on Incidence and Prevention", Sports Med., 34, pp. 929 - 938, (2004).

11. Fuller C. W., Clarke L., Molloy M. G., "Risk of Injury Associated with Rugby Union Played on Artificial Turf", J. Sports Sci. 28, pp. 563 - 570, (2010).

12. Burillo P., Gallardo L., Felipe J.L., Gallardo A.M., "Artificial Turf Surfaces: Perception of Safety, Sporting Feature, Satisfaction and Preference of Football Users", Eur. J. Sport Sci. 14, S437 - S447, (2014).

13. Van der Heide E., Lossie C. M., Van Bommel K. J. C., Reinders S. A. F., Lenting H. B. M., "Experimental Investigation of a Polymer Coating in Sliding Contact with Skin Equivalent Silicone Rubber in an Aqueous Environment, Tribol. Trans., 53, pp. 842- 847, (2010).

14. Felipe J.L., Gallardo L., Burillo P., Gallardo A., Sánchez J. S., Carmona M. P., "Artificial Turf Football Fields: A Qualitative Vision for Professionals Players and Coaches, S. Afr. J. Res. Sport Ph., 35, (2), pp. 105 - 120, (2013).

15. Charalambous L., Wilkau H., Potthast W., Irwin G., "The Effects of Artificial Surface Temperature on Mechanical Properties and Player Kinematics during Landing and Acceleration", J. Sport Health Sci., 5, (3), pp. 355 - 360, (2016).

16. James I. T., McLeod A. J., "The Effect of Maintenance on the Performance of SandFilled Synthetic Turf Surfaces", Sports Technol., 3, (1), pp. 43 - 51, (2010).

17. Eijnde W. V. D., Peppelman M., Weghuis M. O., Erp P. E., "Psychosensorial Assessment of Skin Damage Caused by a Sliding on Artificial Turf: The Development and 
Validation of a Skin Damage Area and Severity Index", Journal of Science and Medicine in Sport, 17, pp. 18 - 22, (2014).

18. American Society for Testing and Materials, "Standard Test Method Relative Abrasiveness of Synthetic Turf Playing Surfaces", F1015-02, Annual Book of ASTM Standards. Vol. 15.07, End Use Products West Conshohocken, PA, ASTM, (2002).

19. FIFA. Determination of Skin/Surface Friction and Skin Abrasion (FIFA test method 08), In: A Quality Concept for Football Turf-Handbook of Test Methods, pp. 33 - 36, (2008).

20. Strutzenberger G., Cao H. M., Koussev J., Potthast W., Irwin G., "Effect of Turf on the Cutting Movement of Female Football Players", Journal of Sport and Health Science, 3, pp. 314 - 319, (2014).

21. Ali A. S. and Ali W. Y. and Samy A. M., "Electrostatic Charge Generated from Sliding on Polyethylene Turf", Journal of the Egyptian Society of Tribology, Vol. 17, No. 1, January 2020, pp. 1 - 13, (2020).

22. Ali A. S., Ali W. Y. and Ibrahem R. A., "Influence of Blending Polyethylene Turf by Copper Textile on Generation of Electrostatic Charge", Journal of the Egyptian Society of Tribology, Vol. 17, No. 3, July 2020, pp. 14 - 25, (2020).

23. Ali A. S., Al-Kabbany A. M., Ali W. Y. and Samy A. M., "Reducing the Electrostatic Charge Generated from sliding of Rubber on Polyethylene Artificial Turf", Journal of the Egyptian Society of Tribology, Vol. 17, No. 2, April 2020, pp. 40 - 49, (2020).

24. Ali A. S., Ali W. Y. and Ibrahem R. A., "Effect of Blending Polyethylene Turf by Polymethyl Methacrylate and Polyamide on Generation of Electrostatic Charge", Journal of the Egyptian Society of Tribology, Vol. 17, No. 2, April 2020, pp. 50 - 60, (2020). 25. Ali A. S., Ali W. Y., Ibrahem R. A. and Ameer A. K., "Effect of Conducting Materials on Electrostatic Charge Generated from Sliding on Polyethylene Turf", Journal of the Egyptian Society of Tribology, Vol. 17, No. 3, July 2020, pp. 48 - 58, (2020). 